\title{
The CHRNA3 rs578776 variant is associated with an intrinsic reward sensitivity deficit in smokers
}

\section{Jason D. Robinson ${ }^{1}$, Francesco Versace ${ }^{1}$, Cho Y. Lam ${ }^{2}$, Jennifer A. Minnix ${ }^{1}$, Jeffrey M. Engelmann ${ }^{1}$, Yong Cui ${ }^{1}$, Maher Karam-Hage ${ }^{1}$, Sanjay S. Shete ${ }^{3}$, Gail E. Tomlinson ${ }^{4}$, Tina T.-L. Chen ${ }^{5}$, David W. Wetter ${ }^{2}$, Charles E. Green ${ }^{6}$ and Paul M. Cinciripini ${ }^{1}$}

\author{
1 Department of Behavioral Science, The University of Texas MD Anderson Cancer Center, Houston, TX, USA \\ 2 Department of Health Disparities Research, The University of Texas MD Anderson Cancer Center, Houston, TX, USA \\ ${ }^{3}$ Department of Biostatistics, The University of Texas MD Anderson Cancer Center, Houston, TX, USA \\ ${ }^{4}$ Division of Pediatric Hematology-Oncology, The University of Texas Health Science Center at San Antonio, San Antonio, TX, USA \\ ${ }^{5}$ Hamon Center for Therapeutic Oncology Research, The University of Texas Southwestern Medical Center at Dallas, Dallas, TX, USA \\ ${ }^{6}$ The University of Texas Medical School at Houston, Houston, TX, USA
}

\section{Edited by:}

Maartje Luijten, Erasmus University Rotterdam, Netherlands

Reviewed by:

Carmelo Mario Vicario, The University of Queensland, Italy

Desiree Spronk, Radboud University Nijmegen Medical Centre,

Netherlands

Marianne Littel, Utrecht University,

Netherlands

*Correspondence:

Jason D. Robinson, Department of Behavioral Science, The University of Texas MD Anderson Cancer Center, P.O. Box 301439, Unit 1330, Houston TX 77030, USA

e-mail: jdrobinson@mdanderson.org
A compromised brain reward system has been postulated as a key feature of drug dependence. We examined whether several polymorphisms of genes found to regulate nicotinic acetylcholine receptor (nAChR) and dopamine expression were related to an intrinsic reward sensitivity (IRS) deficit we previously identified among a subgroup of smokers using event-related potentials (ERPs). We examined genetic polymorphisms within the CHRNA5A3-B4 gene cluster (CHRNA3 rs578776, CHRNA5 rs16969968, LOC123688 rs8034191, and CHRNA3 rs 1051730), the ANKK1 gene (rs1800497), and the $\mathrm{D}_{2}$ dopamine receptor gene (DRD2 rs1079597, DRD2 rs1799732) from 104 smokers of European ancestry in a smoking cessation trial. Prior to treatment, we recorded ERPs evoked by emotional (both pleasant and unpleasant), neutral, and cigarette-related pictures. Smokers were assigned to two groups (IRS+/IRS-) based on the amplitude of the late positive potential (LPP) component to the pictures, a neural marker of motivational salience. Smokers $(n=42)$ with blunted brain responses to intrinsically rewarding (pleasant) pictures and enhanced responses to cigarette pictures were assigned to the IRS - group, while smokers $(n=62)$ with the opposite pattern of LPP responding were assigned to the IRS+ group. Carriers of the protective minor $T$ allele (T/T, C/T) of the CHRNA3 rs578776 were less likely to be members of the IRS - group than those homozygous for the at-risk $C$ allele $(C / C)$. The CHRNA3 rs578776 polymorphism did not differ on questionnaires of nicotine dependence, depressed mood, or trait affective disposition and did not predict abstinence at 6 months after the quit date. These results suggest that polymorphisms of genes influencing nAChR expression are related to an endophenotype of reward sensitivity in smokers.

Keywords: nAChR, DRD2, nicotine, reward sensitivity, ERP, LPP, smoking cessation, genetics

\section{INTRODUCTION}

A compromised brain reward system has been postulated as a key feature of drug dependence. Volkow and Colleagues (1-3) proposed that, due to the supraphysiological dopamine (DA) release in the midbrain resulting from drug use, addiction leads to overvaluing drug-related stimuli and to undervaluing intrinsically rewarding stimuli (e.g., food, sex), a condition we refer to as reduced intrinsic reward sensitivity (IRS-). The evidence for this differential salience is mixed. While many studies have found evidence for the enhanced motivational salience of drug-related stimuli among the drug dependent compared to controls (4-7), not all do $(8,9)$. Few studies have examined whether there is a concomitant reduction in the salience of intrinsically rewarding stimuli among the drug dependent. Of those that have, some have found that the drug dependent show enhanced salience to drug stimuli and reduced salience to intrinsically rewarding stimuli compared to controls (10-12), though other findings in the animal $(13,14)$ and human $(15-17)$ literatures are equivocal.
Recently, using event-related potentials (ERPs), we found that smokers who demonstrated IRS- were more likely to relapse following a smoking cessation intervention than smokers with "normal" intrinsic reward sensitivity [IRS+; (18)]. We identified this endophenotype by analyzing smokers' ERP differences to motivationally relevant visual stimuli. Baseline brain responses to unpleasant, neutral, pleasant, and cigarette-related (CIG) pictures were measured using the late positive potential (LPP). The LPP is an ERP component that peaks between 400 and $700 \mathrm{~ms}$ after stimulus onset and reliably indexes the motivational salience of passively viewed affective pictures (19-23). Consistent with the idea that after repeated drug use drug-related cues acquire motivational significance $(2,3,24)$, smokers produce LPP responses to CIG pictures that are larger than those to neutral pictures (16, 25-27). However, by grouping smokers using individual patterns of brain reactivity, we discovered that while all smokers show larger LPP responses to cigarette than to neutral stimuli, a sizable number of them ( $45 \%$ of our sample) also show blunted 
brain responses to pleasant stimuli. Importantly, these individual differences in responsivity to pleasant stimuli predict subsequent smoking abstinence, such that smokers with blunted brain responses to intrinsically pleasant stimuli (IRS-) had significantly lower rates of long-term smoking abstinence than smokers with normal responses to pleasant stimuli (IRS+).

Our findings suggest that a large portion of smokers have blunted brain responses to intrinsically rewarding stimuli, but it is unclear why certain smokers have this presumed deficit while others do not. Genetic factors, particularly those that influence and regulate DA-mediated reward signaling, are likely targets. While nicotine dependence involves numerous neuroadaptations, the binding of nicotine to nicotinic acetylcholine receptors (nAChRs) on dopaminergic neurons in the ventral tegmental area (VTA) is thought to be key to nicotine's effects on motivation (28). Nicotine binding on VTA dopaminergic neurons leads to increased DA burst firing, resulting in DA release in the outer shell of the nucleus accumbens (NAcc), a part of the mesolimbic reward pathway (29).

One possible source for this IRS- endophenotype is reduced striatal $\mathrm{D}_{2}$ DA receptor (D2R) density. A model that links striatal $\mathrm{D} 2 \mathrm{R}$ deficits, $\mathrm{D}_{2}$ dopamine receptor (DRD2) (and ANKK1) genes, and substance abuse is the "reward deficiency syndrome" (RDS) model by Blum and Colleagues $(30,31)$. In the RDS model, individuals with deficits in DRD2 receptor genes experience less reward and enjoyment from day-to-day activities (i.e., anhedonia) and are prone to substance dependence to increase DA levels and hedonic tone. The RDS model predicts that those with D2R deficits should experience greater enjoyment of drugs that stimulate DA release, which has been largely supported. For example, among drug-naive individuals, those with the lower striatal D2R density were more likely to report enjoying the novel effects of the psychostimulant methylphenidate $(32,33)$ compared with those with higher levels. However, research involving participants with chronic mental illness suggest that D2R deficits do not result in anhedonia, as suggested by the RDS model, but instead result in affective flattening $(34,35)$. Affective flattening is thought to reflect a reduction in the incentive salience of intrinsically pleasant stimuli and is consistent with the Incentive Salience model's concept of "wanting" (24). This increase in drug reinforcement and decrease in responding to intrinsically rewarding cues appears to map onto the IRS - endophenotype and led us to examine whether genes that inform D2R expression could explain the differences we found.

The DRD2 gene and the adjacent $A N K K 1$ gene have been linked to $\mathrm{D} 2 \mathrm{R}$ deficits, nicotine dependence, and reward sensitivity. The $D R D 2$ gene is located on chromosome 11q22-q23 and three of the more frequently studied polymorphisms in the addictive disorders have been the ANKK1 rs1800497, DRD2 rs1799732 (-141C Ins/Del), and DRD2 rs1079597 (TaqI-B). The ANKK1 rs1800497, formerly known as the DRD2 TaqI-A, is a protein kinase gene located 9.5-kb downstream from the DRD2 locus on chromosome 11 (36). Those carrying the T (A1) allele have fewer striatal D2R receptors compared to those without the $\mathrm{T}$ allele (37). The deletion variant of the DRD2 rs1799732, located in the $5^{\prime}$ promoter region, has been associated with lower promoter activity (38). The biological significance of the DRD2 rs1079597, located in intron 1, 913 bp from the exon 2 start codon, is unknown (39). The ANKK1 rs 1800497 has been linked to nicotine dependence in some $(40,41)$, but not all (42), studies. The ANKK1 rs1800497, DRD2 rs1079597, and DRD2 rs1799732, have been found to predict the severity of smoking withdrawal $(43,44)$ and to moderate the effects of bupropion $(45,46)$ and nicotine replacement therapy [NRT; $(46,47)$ ] on smoking cessation, though recent work has either failed to find a relationship between the ANKK1 rs1800497 and smoking cessation outcome (42) or found a relationship with cessation only in subgroups such as women (48) or the depressed (49). In terms of the brain's reward system, the ANKK1 rs1800497 has been found to be related to smoking enjoyment (50) and to smoking with the intent of reducing negative affect (51), suggesting that it directly affects nicotine reinforcement.

Striatal DA functioning is impacted by nicotine (52) through its high affinity for $\alpha 4 \beta 2$-containing nAChRs in the VTA (53). Activation of the $\alpha 3$ (54), $\alpha 4$ (55), $\alpha 6$ (56), $\alpha 7$ (57), and $\beta 2$ (58) nAChR subunits has been found to enhance nicotine reinforcement. In terms of intrinsic reward sensitivity (IRS), nicotine exposure has been found to lower the threshold for intrinsic reward for at least 30 days in rodents (59). In humans, indirect evidence comes from a study that found that schizophrenic smokers with greater baseline symptoms of affective flattening were more likely to benefit from treatment by varenicline, an $\alpha 4 \beta 2$ nAChR partial agonist, benefits that included increased abstinence and larger increases in reward sensitivity (60). The nAChR genes that have been most associated with smoking in many population studies are the CHRNA5-A3-B4 gene cluster located on chromosome 15q25.1. The CHRNA5 rs16969968 (a non-synonymous coding SNP in exon 5), the CHRNA3 rs578776 ( $3^{\prime}$ UTR), the CHRNA3 rs1051730 (a synonymous SNP in exon 5), and the rs8034191 (located in intron 2 of hypothetical gene LOC123688) are located in a region of strong linkage disequilibrium (LD) and have been found to be related to smoking and smoking heaviness (6163). The CHRNA5 rs16969968, the CHRNA3 rs578776, CHRNA3 rs 1051730, and the LOC123688 rs8034191 have all been found to be related to smoking rate and other measures of nicotine dependence (61-63). While none of the CHRNA5-A3-B4 genetic subunits have been shown to directly influence functioning of the VTA or other areas associated with the brain's reward system, recent evidence from transgenic mice found that overexpressing the human CHRNA5/A3/B4 gene cluster led to increased nicotine self-administration (64), suggesting a direct link between this cluster and nicotine reinforcement.

In the present study, we investigated whether DRD2 and nAChR genetic variants known to influence striatal DA functioning and smoking behavior accounted for the reward sensitivity endophenotype we recently identified in smokers (18). We examined the relationship between this IRS endophenotype, comprised of ERP measures of motivational salience, and genetic polymorphisms within the CHRNA5-A3-B4 gene cluster (CHRNA3 rs578776, CHRNA5 rs16969968, LOC123688 rs8034191, and CHRNA3 rs 1051730), the ANKK1 gene (rs1800497), and the $\mathrm{D}_{2}$ receptor gene (DRD2 rs1799732, DRD2 rs1079597), from 104 smokers of European ancestry in a smoking cessation trial [ClinicalTrials.gov Identifier: NCT00507728; (65)]. We hypothesized that smokers carrying at-risk $\mathrm{nAChR}, A N K K 1$, or $\mathrm{D}_{2}$ receptor alleles (i.e., alleles previously linked to smoking behavior and nicotine dependence) would be more likely to be in the IRS- group, as assessed by ERP 
to motivational stimuli, compared to those without these alleles. We also assessed the incremental impact of possessing multiple atrisk alleles on our ability to predict IRS group membership, using receiver-operator curve (ROC) analysis.

\section{MATERIALS AND METHODS PARTICIPANTS}

We recruited smokers from the community who were seeking to quit smoking. Inclusion criteria included being aged $18-65$ years, smoking five or more cigarettes per day, producing a baseline expired carbon monoxide (CO) level $\geq 6 \mathrm{ppm}$, having fluency in English, and having a working telephone. Conditions that excluded participants included taking psychotropic medication, having a current psychiatric disorder (including substance abuse or dependence, other than nicotine dependence), being involved in any smoking cessation activities (e.g., NRT, counseling) except those provided by the clinical trial, having contraindications for either bupropion or varenicline, or having any uncontrolled medical illness. Psychiatric disorders were assessed using the MiniInternational Neuropsychiatric Interview (66). Of the 294 enrolled in the clinical trial (65), 208 eligible participants completed a baseline laboratory ERP session, but only 180 yielded usable ERP data and were included in our previous report describing the reinforcement sensitivity construct (18). A total of 24 were excluded because of poor recording quality and 4 because of technical errors. Of those 180 from our previous study, 104 were of self-reported European ancestry and subject to the analyses described herein (data from the 49 participants of African ancestry differed significantly from those of European ancestry on several of the genotype frequencies and were excluded from further analyses). Participants provided written informed consent, and the protocol and informed consent document were approved by The University of Texas MD Anderson Cancer Center Institutional Review Board.

\section{PROCEDURES}

Participants were screened for eligibility a week before the baseline laboratory session. Participants were instructed to smoke ad libitum before the baseline laboratory session. At the baseline laboratory session, participants provided an expired carbon monoxide (CO) sample, provided a buccal sample, and completed questionnaires including the Fagerström Test for Nicotine Dependence [FTND; (67)], the Wisconsin Inventory of Smoking Dependence Motives [WISDM; (68)], the Center for Epidemiologic Studies Depression Scale [CES-D; (69)], the Depression Proneness Inventory [DPI; (70)], the Behavioral Inhibition System/Behavioral Activation System (BIS/BAS) scales (71) and the Fawcett-Clark Pleasure Scale [FCPS; (72)]. Next, the participants had the electroencephalogram (EEG) electrodes applied and were instructed to keep their eyes on the screen during the pictureviewing task, to move as little as possible, and to ignore the intermittent auditory startle probe noises delivered through the earphones during the picture viewing.

\section{Picture-viewing task}

During the 30-min picture-viewing task, participants viewed 1 of 3 picture sets composed of 4 picture categories, including pleasant (PLE), unpleasant (UNP), CIG, and neutral (NEU), with 24 pictures in each category ( 96 total pictures per set). The three picture sets were comprised of pictures from the International Affective Picture System (IAPS) (73), the International Smoking Image Series (ISIS) (74), and the Normative Appetitive Picture System (NAPS) (75). We supplemented these sets using pictures generated by our laboratory, some of which were previously published (76). Each set of 96 pictures included 24 pictures in 4 categories (PLE, UNP, NEU, CIG). Each picture category included 16 pictures depicting human beings and 8 without a person. In terms of semantic content, the PLE category was comprised of erotic couples (high arousal), romantic couples (low arousal), and pleasant objects (e.g., food, landscapes; low arousal), UNP category of mutilations (high arousal), sad scenes (e.g., grief, disease; low arousal), and unpleasant objects (e.g., pollution, accidents; low arousal), NEU category of neutral people and objects (e.g., household objects), and the CIG category of people smoking and CIG objects (e.g., lit cigarettes in ashtrays). The arousal ratings of the PLE and UNP pictures, which were primarily taken from the IAPS set (see Table 1), are from published IAPS normative ratings (73). Pictures were presented for $4 \mathrm{~s}$, separated by a random inter-trial interval of 3-5 s, in pseudo-random sequences with no more than two pictures of the same category presented consecutively. Each picture was presented twice during the session to increase the ERP signal-to-noise ratio. Six (25\%) the 24 pictures in each category included a $50-\mathrm{ms} 100 \mathrm{~dB}(\mathrm{~A})$ white noise auditory startle probe that occurred between 2.5 and $3.5 \mathrm{~s}$ after picture onset. These probes occur substantially after the ERP component of interest here (400$700 \mathrm{~ms}$ ) and as such did not impact the ERPs to the pictures and hence are not discussed in this report. Stimuli were presented with a Pentium 4 computer using E-prime software (v1.4; Psychology Software Tools, Inc., Pittsburgh, PA, USA) on a plasma screen placed approximately $1.5 \mathrm{~m}$ from the participant's eyes. The entire picture-viewing session lasted approximately $30 \mathrm{~min}$.

\section{ERP data collection and scoring}

Details of the EEG collection, offline scoring, and cluster analysis are reported in Versace et al. (18) and summarized here. We collected EEG during the picture-viewing task using a 129-channel EEG net and AC-coupled high-input impedance (200 M $\Omega$ ) amplifier (Geodesic EEG System 200, Electrical Geodesics Inc., Eugene, OR, USA) referenced to the $\mathrm{Cz}$ electrode site. EEG was sampled at $250 \mathrm{~Hz}$ and filtered online using $0.1-\mathrm{Hz}$ high-pass and $100-\mathrm{Hz}$ lowpass filters, and the scalp impedance of each sensor was brought below $50 \mathrm{k} \Omega$, as suggested by the manufacturer.

Offline scoring included the following procedures: (1) application of a $30-\mathrm{Hz}$ low-pass filter; (2) visual inspection of the data, with channels contaminated by artifacts for more than $50 \%$ of the recording interpolated using spherical splines; (3) application of a spatial filtering method (77) to correct for eye blinks; (4) re-referencing to the average reference (78); (5) segmentation of the EEG data using a 900-ms epoch with a 100-ms baseline preceding the picture; (6) removal of segments if more than $10 \%$ of the sensors were contaminated by artifacts, defined as EEG amplitude above 100 or below $-100 \mathrm{mV}$, voltage difference between any two adjacent samples larger than $100 \mathrm{mV}$, voltage difference between two adjacent samples above $25 \mathrm{mV}$, or variation of $<0.5 \mathrm{mV}$ for more than $100 \mathrm{~ms}$; (7) calculation of the mean LPP amplitude between 400 and $700 \mathrm{~ms}$ after picture onset for each 
Table 1 | List of pictures used in the picture-viewing task, by picture category and source.

\begin{tabular}{|c|c|c|c|}
\hline Source & PLE & UNP & NEU \\
\hline PS & $\begin{array}{l}2208,4599,4610,4611,4623, \\
4624,4625,4626,4640, \\
4641,4643,4645,4647, \\
4649,4650,4653,4658, \\
4659,4660,4666,4669, \\
4676,4677,4680,4687,4689, \\
4690,4691,4693,4694, \\
4695,4696,4698,4700, \\
4800,4810,5250,5626, \\
5628,5629,5631,5660, \\
5661,5700,5711,5764, \\
5780,5781,7270,7330, \\
7340,7350,7410,7430,7450, \\
7460,7470,7480,7482,7485\end{array}$ & $\begin{array}{l}2095,2141,2205,2276,2399, \\
2455,2490,2491,2520,2590, \\
2700,2703,2800,2810,2900, \\
3000,3030,3051,3053,3060, \\
3068,3069,3080,3100,3101, \\
3102,3110,3120,3130,3140, \\
3168,3170,3225,3261,3280, \\
3300,3350,6000,6020,6190, \\
6200,6210,6230,6260,6410, \\
9010,9090,9110,9190,9253, \\
9265,9290,9300,9301,9320, \\
9373,9390,9410,9420,9421, \\
9429,9433,9520,9530,9560, \\
9600,9620,9621,9901,9911, \\
9912,9926\end{array}$ & $\begin{array}{l}2102,2104,2190,2191,2200, \\
2210,2214,2215,2220,2221, \\
2230,2235,2305,2312,2358, \\
2372,2383,2393,2396,2397, \\
2435,2441,2485,2493,2495, \\
2499,2500,2510,2512,2513, \\
2515,2570,2575,2579,2593, \\
2594,2595,2597,2598,2600, \\
2630,2830,2850,7000,7002, \\
7004,7006,7009,7010,7020, \\
7030,7034,7038,7040,7041, \\
7052,7053,7054,7055,7056, \\
7059,7080,7090,7110,7130, \\
7140,7550,9070\end{array}$ \\
\hline
\end{tabular}

ISIS

$001,003,004,007,008,010,016$, 017, 019, 020, 022, 029, 030, 031, $033,034,038,047,055,058,062$, $063,068,070,073,081,088,089$, 091, 092, 093, 097, 099, 100, 101, $103,104,106,107,108,111,115$, $116,118,120$

101,106

NAPS

Internal (12 Pictures)

(0 Pictures)

(4 Pictures)

IAPS, International Affective Picture System (73); ISIS, International Smoking Image Series (74); NAPS, Normative Appetitive Picture System (75). The internal pictures were generated by our laboratory, some of which were previously published (76), and are available upon request.

category (UNP, NEU, PLE, CIG) for each participant by averaging over 10 sensors in the central and parietal regions with the largest LPP differences between neutral and motivationally relevant (UNP/PLE/CIG) pictures. We analyzed the LPP within the 400- to 700-ms time window because it is considered the time window within which the LPP differences among categories peak and it is routinely used in studies investigating ERP responses to emotional and neutral stimuli $(21,22,79-81)$. Moreover, increasing the length of the time window would have increased the number of epochs discarded because of the presence of artifacts, which could have reduced the reliability of the results without significantly improving the power to detect differences among the stimuli.

\section{ERP cluster analyses}

Details of the LPP cluster analysis are reported in Versace et al. (18). The four category LPP means from each participant were entered into a cluster analysis ( $k$-means method) to assign smokers to two groups (IRS group) based on their brain responses to the experimental visual stimuli. Cluster analysis is a group of multivariate techniques whose purpose is to assemble objects (i.e., participants) based on the response patterns of several characteristics (82). A two-cluster solution was selected a priori because we hypothesized that smokers would differ on the basis of their sensitivity to intrinsically pleasant stimuli, which resulted in 99 participants assigned to Cluster 1 and 81 participants to Cluster 2. To evaluate if the two-cluster solution was appropriate, we used Euclidean distances and the Hartigan and Wong (83) algorithm for solutions ranging from 2 to 15 clusters. The Cubic Clustering Criterion (84) and the Duda-Hart Index (85), two commonly used stopping rules for iterative clustering, both indicated that the twocluster solution was optimal. We next conducted an ANOVA using cluster (Cluster 1 vs. 2) as a between-subjects factor and picture type (UNP, NEU, PLE, CIG) as a within-subjects factor and found a significant two-way interaction, $F(3,534)=43.49, p<0.0001$. Post hoc contrasts indicated that LPP to pleasant pictures were significantly smaller in Cluster $2(M=1.76 S E=0.17)$ than in Cluster $1(M=2.95, \mathrm{SE}=0.16 ; p<0.0001)$, but that CIG pictures were somewhat larger LPP in Cluster $2(M=2.47, \mathrm{SE}=0.16)$ than in Cluster $1(M=1.81, \mathrm{SE}=0.15 ; p<0.10)$. The two clusters did not differ on LPPs to either neutral or unpleasant pictures. We refer to Cluster 1 as the "normal" IRS cluster (IRS+) and Cluster 2 as the reduced IRS cluster (IRS-).

\section{Genotyping}

Genomic DNA was extracted from buccal cells by using the QIAmp DNA kit (cat. \# 51185; QIAGEN Sciences, Valencia, CA, USA). Single nucleotide polymorphism genotyping of the DA and nAChR SNPs was performed using the $5^{\prime}$ nuclease assay 
to discriminate between the two alleles representing the different genotypes. The assay reagents for SNP genotyping consisted of a mix of PCR primers and TaqMan MGB probes (FAM and VIC labeled) that were obtained from Applied Biosystems (Foster City, CA, USA). TaqMan SNP Genotyping Assays (ABI) were used for the polymorphisms ANKK1 rs1800497 (C_7486676_10), DRD2 rs1079597 (C_2278884_10), CHRNA5 rs16969968 (C_26000428_20), CHRNA3 rs578776 (C_721253_10), CHRNA3 rs1051730 (C_9510307_20), and LOC123688 rs8034191 (C_479126_10). Probes and primer for the DRD2 rs1799732 polymorphism were designed in-house (Probe 1: FAMTACCCGTTCCAGGCCMGBNFQ; Probe 2: VICTACCCGTTCAGGCCGMGBNFQ; Primer 1: AAACAAGGGATGGCGGAAT; Primer 2: CCCCACCAAAGGAGCTGTA). Each assay enables scoring of both alleles in a single well within a 384-well plate. All assays are optimized to work with genomic DNA and TaqMan Universal Master Mix from Applied Biosystems. Forty cycles of PCR were performed. Plates were analyzed using an ABI Prism 7900HT Sequence Detection System from Applied Biosystems.

\section{Statistical analysis}

The tests of Hardy-Weinberg Equilibrium (HWE) and LD, and frequencies by allele and genotype, were completed using SAS Proc Allele (v9.2; SAS Institute, Carey, NC, USA). We used chisquare tests to examine dominant (homozygous wild type vs. heterozygotes and homozygous variants) and recessive (homozygous variant vs. heterozygotes and homozygous wild type) models of gene action on IRS group membership, with the interpretation of statistical significance adjusted for multiple comparisons using the Bonferroni correction. We used $t$-tests to evaluate differences in baseline measures by genotype and IRS group, with Satterthwaite's approximation for degrees of freedom when variance was unequal.

\section{RESULTS}

\section{ALLELE AND GENOTYPE FREOUENCIES}

The tests of HWE and LD, and frequencies by allele and genotype for the participants of European ancestry are reported in Table 2. The frequencies of the DRD2 rs1079597 (TaqI-B) and DRD2 rs1799732 (-141C Ins/Del) did not meet HWE criteria but were included in further analyses for exploratory purposes. In terms of LD, the CHRNA5 rs16969968, LOC123688 rs8034191, CHRNA3 rs578776, and CHRNA3 rs1051730 SNPs were all found to be in strong LD with each other ( $r$ range: $0.53-0.97)$. The DRD2 rs1079597 was in LD with the ANKK1 rs1800497, $r=0.96$. The CHRNB2 rs2072661 and DRD2 rs1799732 were not in LD with the other SNPs.

\section{BASELINE CHARACTERISTICS, BY IRS GROUP}

For this sample of 104 smokers of European ancestry, we assigned IRS group membership based on the cluster solution from our full $(n=180)$ sample (18). We analyzed our baseline questionnaires by IRS group, and found that IRS - smokers produced significantly higher expired CO values than IRS+ smokers, Satterthwaite $t(60.43)=2.03, p<0.05$ (see Table 3 ). The IRS groups did not differ on any other measure.
Table 2 | Tests of Hardy-Weinberg equilibrium and frequencies by allele and genotype for the participants of European ancestry.

\begin{tabular}{|c|c|c|c|c|c|}
\hline \multirow{2}{*}{$\begin{array}{l}\text { Gene/SNP } \\
\text { Allele/genotype }\end{array}$} & \multicolumn{2}{|c|}{ Frequency } & \multicolumn{3}{|c|}{$\begin{array}{l}\text { Hardy-Weinberg } \\
\text { equilibrium }\end{array}$} \\
\hline & $n$ & $\%$ & $x^{2}$ & $d f$ & $p$ Value \\
\hline ANKK1 rs1800497 & & & 0.00 & 1 & 1.00 \\
\hline $\mathrm{T}$ & 48 & 25.0 & & & \\
\hline C & 144 & 75.0 & & & \\
\hline$T / T$ & 6 & 6.3 & & & \\
\hline $\mathrm{T} / \mathrm{C}$ & 36 & 37.5 & & & \\
\hline $\mathrm{C} / \mathrm{C}$ & 54 & 56.3 & & & \\
\hline DRD2 rs1079597 & & & 8.46 & 1 & 0.004 \\
\hline A & 59 & 30.7 & & & \\
\hline G & 133 & 69.3 & & & \\
\hline $\mathrm{A} / \mathrm{A}$ & 3 & 3.1 & & & \\
\hline$A / G$ & 53 & 55.2 & & & \\
\hline $\mathrm{G} / \mathrm{G}$ & 40 & 41.7 & & & \\
\hline DRD2 rs1799732 & & & 5.46 & 1 & 0.05 \\
\hline Ins & 171 & 90.0 & & & \\
\hline Del & 19 & 10.0 & & & \\
\hline Ins/Ins & 79 & 83.2 & & & \\
\hline Ins/Del & 13 & 13.7 & & & \\
\hline Del/Del & 3 & 3.2 & & & \\
\hline CHRNA5 rs16969968 & & & 1.17 & 1 & 0.39 \\
\hline$A$ & 71 & 35.2 & & & \\
\hline $\mathrm{G}$ & 131 & 64.8 & & & \\
\hline $\mathrm{A} / \mathrm{A}$ & 10 & 9.9 & & & \\
\hline$A / G$ & 51 & 50.5 & & & \\
\hline $\mathrm{G} / \mathrm{G}$ & 40 & 39.6 & & & \\
\hline CHRNA3 rs 1051730 & & & 0.57 & 1 & 0.52 \\
\hline$A$ & 71 & 35.9 & & & \\
\hline G & 127 & 64.1 & & & \\
\hline $\mathrm{A} / \mathrm{A}$ & 11 & 11.1 & & & \\
\hline$A / G$ & 49 & 49.5 & & & \\
\hline $\mathrm{G} / \mathrm{G}$ & 39 & 39.4 & & & \\
\hline CHRNA3 rs578776 & & & 1.23 & 1 & 0.26 \\
\hline T & 45 & 22.5 & & & \\
\hline C & 155 & 77.5 & & & \\
\hline $\mathrm{T} / \mathrm{T}$ & 7 & 7.0 & & & \\
\hline $\mathrm{C} / \mathrm{T}$ & 31 & 31.0 & & & \\
\hline $\mathrm{C} / \mathrm{C}$ & 62 & 62.0 & & & \\
\hline CHRNB2 rs2072661 & & & 0.87 & 1 & 0.43 \\
\hline A & 50 & 25.0 & & & \\
\hline G & 150 & 75.0 & & & \\
\hline $\mathrm{A} / \mathrm{A}$ & 8 & 8.0 & & & \\
\hline$A / G$ & 34 & 34.0 & & & \\
\hline $\mathrm{G} / \mathrm{G}$ & 58 & 58.0 & & & \\
\hline LOC123688 rs8034191 & & & 0.98 & 1 & 0.40 \\
\hline $\mathrm{C}$ & 70 & 35 & & & \\
\hline $\mathrm{T}$ & 130 & 65 & & & \\
\hline $\mathrm{C} / \mathrm{C}$ & 10 & 10 & & & \\
\hline $\mathrm{C} / \mathrm{T}$ & 50 & 50 & & & \\
\hline $\mathrm{T} / \mathrm{T}$ & 40 & 40 & & & \\
\hline
\end{tabular}


Table 3 | Baseline demographics, smoking, and affective characteristics, by IRS group $(n=104)$.

\begin{tabular}{lll}
\hline & \multicolumn{2}{c}{ IRS group } \\
\cline { 2 - 3 } Characteristic & IRS+ & IRS- \\
\hline $\boldsymbol{n}(\%)$ & $62(59.6)$ & $42(40.4)$ \\
Total $n$ & $17(27.4)$ & $16(38.1)$ \\
Female & $7(11.3)$ & $5(9.5)$ \\
Positive depression history & & \\
MEAN (SD) & $44.34(11.2)$ & $44.95(10.6)$ \\
Age & $24.60(12.0)$ & $26.67(10.8)$ \\
Years of smoking & $21.13(8.4)$ & $21.79(8.1)$ \\
Cigarettes/day & $23.85(9.1)$ & $29.21(15.42)^{a}$ \\
Expired CO (ppm) & $4.71(2.3)$ & $5.19(2.2)$ \\
FTND score & $44.45(10.2)$ & $46.35(9.3)$ \\
WISDM (total score) & $7.52(6.1)$ & $7.57(6.2)$ \\
CES-D (total score) & $2.61(1.0)$ & $2.70(1.1)$ \\
Depression proneness inventory & $3.68(0.4)$ & $3.74(0.3)$ \\
Fawcett-Clark Pleasure Scale & $26.97(5.8)$ & $28.50(4.8)$ \\
BAS & $14.89(3.5)$ & $15.17(2.9)$ \\
BIS & & \\
& &
\end{tabular}

${ }^{a}$ Significant t-test comparison, by IRS group, at $\alpha<0.05$ (uncorrected). CO, carbon monoxide; FTND, Fagerström test for nicotine dependence; WISDM, Wisconsin inventory of smoking dependence motives; CES-D, the center for epidemiologic studies' depression scale; BAS, behavioral approach system; BIS, behavioral inhibition system.

\section{LPP AMPLITUDE, BY IRS GROUP AND PICTURE CATEGORY}

To verify the differential responsivity by IRS group to cigarette and pleasant pictures in the present sample, we conducted an ANOVA on the 104 smokers of European ancestry using IRS group [IRS $+(n=62)$ vs. IRS $-(n=42)]$ as a between-subjects factor, picture category (UNP, NEU, PLE, CIG) as a within-subjects factor, and mean LPP amplitude (between 400 and $700 \mathrm{~ms}$ after picture onset) as the dependent variable. We found a significant main effect of picture category, $F(4,415)=20.98, p<0.0001$ (see Figure 1), and two-way IRS group by picture category interaction, $F(3,408)=15.52, p<0.0001$ (see Figure 2). Comparable to the results from the full sample of 180 smokers (18), the post hoc contrasts for the 104 smokers of European ancestry indicated that LPPs to pleasant pictures were significantly smaller in IRS- smokers $(M=2.01 \mu \mathrm{V}, \mathrm{SD}=1.34)$, than in IRS+ smokers $(M=3.47 \mu \mathrm{V}$, $\mathrm{SD}=1.67 ; p<0.0001)$. LPPs to $\mathrm{CIG}$ pictures were somewhat larger in IRS $-(M=2.66 \mu \mathrm{V}, \mathrm{SD}=1.27)$ than in IRS+ smokers $(M=2.21 \mu \mathrm{V}, \mathrm{SD}=1.59)$, but the difference was not statistically significant $(p<0.13)$. The two IRS groups did not differ on LPPs to either neutral or unpleasant pictures. Covarying expired $\mathrm{CO}$ did not alter the significant findings.

\section{GENE BY IRS GROUP}

The ORs and 95\% CIs for IRS group membership by genotype (dominance models) are depicted in Table 4. After correcting for multiple comparisons, only the CHRNA3 rs578776 was significant, with carriers of the protective minor $\mathrm{T}$ allele (T/T, C/T) less likely to be in the IRS- group than those homozygous for the

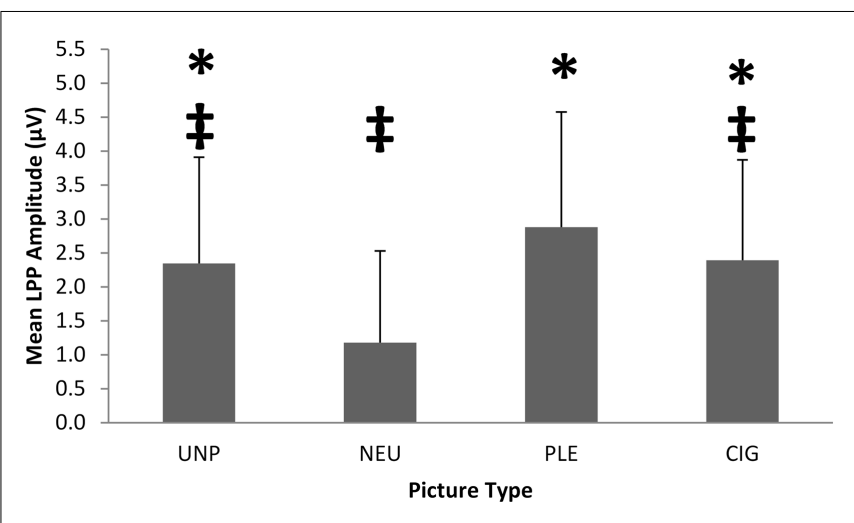

FIGURE 1 | The significant picture category (UNP, NEU, PLE, CIG) main effect on mean LPP amplitude for 104 smokers of European ancestry. The error bars depict standard deviations. *Significantly different from NEU. ${ }^{\ddagger}$ Significantly different from PLE.

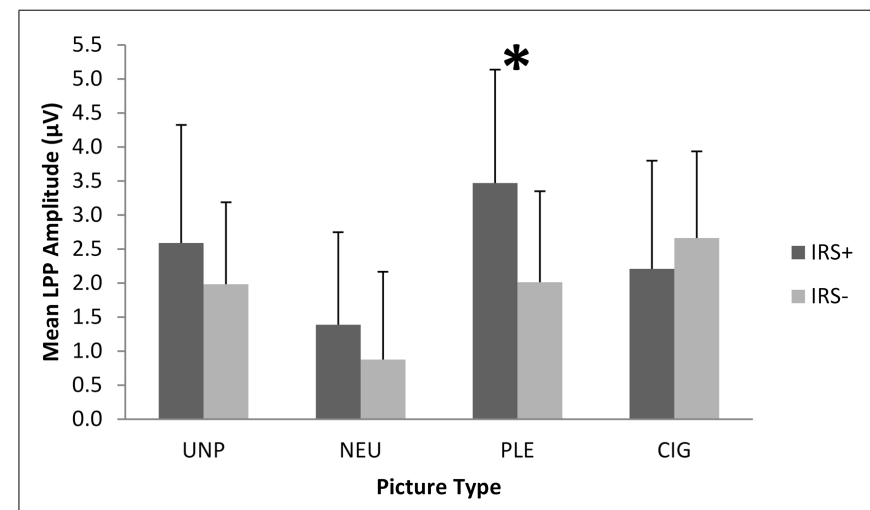

FIGURE 2 |The IRS group (IRS+ vs. IRS-) by picture category (UNP, NEU, PLE, CIG) interaction on mean LPP amplitude. The error bars depict standard deviations. ${ }^{*}$ Significant pairwise comparison, $p<0.0001$.

at-risk C allele $(\mathrm{C} / \mathrm{C}), \mathrm{OR}=0.17,95 \% \mathrm{CI}$ 0.07-0.46 (see Figure 3 for CHRNA3 rs578776 ERP waveforms). Carriers of the at-risk $\mathrm{T}$ (A1) minor allele (T/T, T/C) of the ANKK1 rs1800497 were more likely to be in the IRS- group than those homozygous for the $\mathrm{C}(\mathrm{A} 2)$ allele $(\mathrm{C} / \mathrm{C}), \mathrm{OR}=2.39,95 \% \mathrm{CI} 1.04-5.52$, but this difference was not significantly different after correcting for multiple comparisons. The CHRNA5 rs16969968's relationship to IRS group approached statistical significance prior to correcting for multiple comparisons, $\mathrm{OR}=2.26,95 \%$ CI $0.97-5.24$, suggesting that carriers of the at-risk A minor allele $(\mathrm{A} / \mathrm{A}, \mathrm{A} / \mathrm{G})$ were more likely to be in the IRS- cluster than those homozygous for the $\mathrm{G}$ allele. The frequencies of the LOC123688 rs8034191, CHRNA3 rs1051730, DRD2 rs1079597, and DRD2 rs1799732 SNPs did not significantly differ by IRS group.

To determine whether the at-risk alleles have an additive impact on the prediction of IRS group membership, we examined the incremental impact of the other polymorphisms we evaluated on the CHRNA3 rs578776's ability to predict IRS group membership, using ROC analysis (86). As reported above, the presence of the protective $\mathrm{T}$ allele decreased the odds of being in the IRS- group 
Table 4 | Chi-square analyses with dominance models (homozygous wild type vs. heterozygotes and homozygous variants) predicting reduced intrinsic reward sensitivity (IRS- membership), all $d f=1$.

\begin{tabular}{lcccc}
\hline Polymorphism & OR & $\mathbf{9 5 \%}$ Cl & $\boldsymbol{\chi}^{\mathbf{2}}$ & Uncorrected $\boldsymbol{p}$ value \\
\hline CHRNA3 rs578776 & 0.17 & $0.07-0.46$ & 13.99 & $0.0002^{\mathrm{a}}$ \\
ANKK1 rs1800497 & 2.39 & $1.04-5.52$ & 4.28 & 0.04 \\
CHRNA5 rs16969968 & 2.26 & $0.97-5.24$ & 3.66 & 0.06 \\
CHRNA3 rs1051730 & 1.97 & $0.84-4.60$ & 2.48 & 0.12 \\
LOC123688 rs8034191 & 1.36 & $0.60-3.09$ & 0.55 & 0.46 \\
CHRNB2 rs2072661 & 0.90 & $0.40-2.01$ & 0.07 & 0.80 \\
DRD2 rs1079597 & 1.40 & $0.60-3.28$ & 0.62 & 0.43 \\
DRD2 rs1799732 & 1.23 & $0.41-4.14$ & 0.14 & 0.71
\end{tabular}

a Statistically significant after correcting for multiple comparisons.
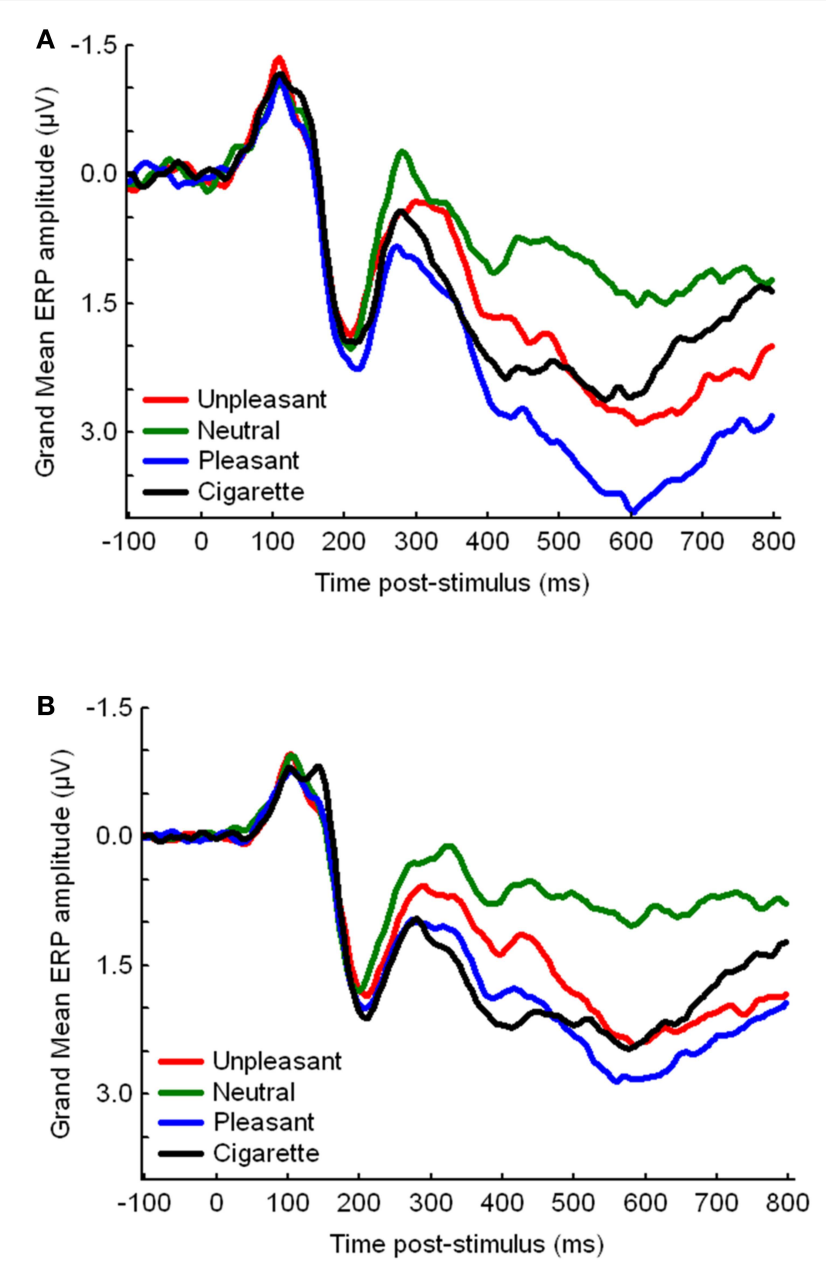

FIGURE 3 | Event-related potential waveforms, by picture category, for CHRNA3 rs578776 (A) carriers of the protective minorT allele (T/T, C/T) and (B) those homozygous for the at-risk $\mathrm{C}$ allele (C/C).

by a factor of $0.17(\mathrm{OR}=0.17,95 \%$ CI $0.07-0.46)$. This corresponded to an area under the curve (AUC) of 0.68. Adding the ANKK1 rs1800497 and CHNRA3 1051730 polymorphisms, as a block, incremented the fit of the model $\left[\Delta \chi^{2}(2)=6.32\right.$, $p<0.04$ ] and increased the AUC to 0.76. These results show that the CHRNA3 rs578776 predicted the IRS endophenotype, and that this prediction may be augmented by adding other SNPs associated with smoking behavior. Including the other polymorphisms did not significantly increase the AUC.

\section{PREDICTION OF ABSTINENCE}

In the original sample of 180 , we found that IRS group predicted abstinence outcome (18), such that IRS- smokers quit smoking less often than did IRS+ smokers. In the current sample of 104 smokers of European ancestry, we verified this relationship using logistic models to compare the smoking abstinence rates of the two IRS groups at 10 weeks, 3 months, and 6 months after the quit date. In this reduced sample, IRS- smokers were also abstinent less often than IRS + at 10 weeks $(\mathrm{OR}=2.73,95 \%$ CI $1.07-$ $6.91)$, 3 months (OR $=3.06,95 \%$ CI $1.19-7.90)$, and 6 months $(\mathrm{OR}=4.03,95 \%$ CI $1.37-11.88)$ after the quit date. There were no significant relationships between any of the SNPs (dominance models) and abstinence at 10-weeks (EOT), 3-months, or 6-months post-quit. There were also no significant interactions between IRS group and SNPs when predicting abstinence at any of the time points.

\section{BASELINE MEASURES, BY GENOTYPE}

To determine whether the participants differed on smoking or affective disposition by genotype, we analyzed our baseline questionnaires by the dominance models for the polymorphisms that differed by IRS group, the ANKK1 rs1800497 and the CHRNA3 rs578776, as well as the CHRNA5 rs16969968. No significant differences ( $p s>0.05$ ) between genotype were found for any of the baseline questionnaires.

\section{DISCUSSION}

These results support the hypothesis that genes associated with nAChR activity are related to a novel neural marker of reward sensitivity in smokers. Carriers of the protective minor $\mathrm{T}$ allele of the CHRNA3 rs578776, a SNP in the CHRNA5-A3-B4 gene cluster on chromosome 15, were significantly less likely to be among those in the IRS- group. Though not statistically significant after correcting for multiple comparisons, carriers of the at-risk ANKK1 rs $1800497 \mathrm{~T}$ (A1) allele or the at-risk CHRNA5 rs16969968 A allele were more likely to be among those in the IRS - group.

Our finding that the protective $\mathrm{T}$ allele of the CHRNA3 rs578776 polymorphism is associated with IRS+ smokers is consistent with previous findings concerning the relationship between that allele and nicotine dependence. The protective minor $\mathrm{T}$ allele of the CHRNA3 rs578776 has been found to be associated with reduced risk for nicotine dependence in EuropeanAmericans (87), but not African-Americans (88), and in smokers who began daily smoking before the age of 17 (89). The protective minor $\mathrm{T}$ allele of the CHRNA3 rs578776 has also been found to be protective against heaviness of smoking $(61,90)$. In an fMRI study, the rs578776 at-risk $\mathrm{C}$ allele was associated with increased activation in a circuit comprising the dorsal anterior cingulate cortex and left anterior thalamus, a circuit that may be sensitive to nicotine exposure or to the alleviation of craving (91). 
Our results suggest that the CHRNA3 rs578776 T allele's protective effect against smoking dependence may be due to its association with normal reward sensitivity to intrinsically pleasant activity in smokers. However, none of the baseline measures of nicotine dependence, depressed mood, or trait affective disposition differed by CHRNA3 rs578776 genotype in the present study. This is unsurprising given that none of these questionnaires differed by IRS group in this and the full samples (18). This suggests that the IRS grouping represents a distinct endophenotype that is not easily captured by self-report and that offers clinical utility as a diagnostic marker of genetic and treatment risk. As we concluded in our previous manuscript (18), this endophenotype could be used to identify smokers who are at greater risk for relapse and who may need cessation interventions tailored to address their hyposensitivity to intrinsically reinforcing stimuli.

There were several null findings that were unexpected. First, some of the polymorphisms most commonly associated with smoking behavior, the ANKK1 rs1800497, CHNRA3 1051730, and CHRNA5 rs16969968, were not significantly related to IRS group. However, the at-risk alleles for these polymorphisms were associated with IRS - membership in the expected direction. They were likely not significant due to inadequate statistical power to detect their weaker effect size compare to that of the CHRNA3 rs578776. Additionally, our ROC analysis found that the likelihood of IRSgroup membership significantly increases with possession of the ANKK1 rs1800497 and CHNRA3 1051730 at-risk alleles, suggesting that these polymorphisms are related to the endophenotype. Second, none of the polymorphisms predicted abstinence outcome, despite the significant associations between IRS group and abstinence at 10-weeks (EOT), 3-months, and 6-months postquit. These findings are not necessarily inconsistent, because an endophenotype such as IRS group membership is likely determined by multiple genetic and environmental factors, as is shown by our ROC analysis.

Previous results largely support models of addiction that postulate that chronic drug use leads to overvaluing drug-related stimuli and undervaluing intrinsically reinforcing stimuli due to the large differential in DA enhancement between the two reinforcers (1-3). However, in a previous study (18), we found that this change in intrinsic reward valuation is not common to all chronic drug users. Our current results suggest that the individual's genetic profile contributes to this variability. Our IRS endophenotype is consistent with Blums' RDS model $(30,31)$ in that a subset of smokers appear to experience increased salience to drug-related stimuli and decreased salience to intrinsically rewarding stimuli. The individual differences reflected in the IRS endophenotype could explain the equivocal findings in the literature, with some $(13,15)$ but not all $(14,92,93)$ studies finding that chronic substance users overvalue the drug compared to natural reinforcers. However, we were unable to conclusively link the IRS - deficit to the reduced D2R density predicted by the RDS model because of the statistically non-significant association between IRS group and the ANKK1 rs 1800497 polymorphism.

These findings are tempered by several limitations of this study. First, while the sample size was large for an ERP study, it was small for a genetic association study. This may explain why two other
SNPs linked with smoking behavior, the ANKK1 rs1800497 and the CHRNA5 rs16969968, produced results suggesting a link between their at-risk variant and blunted brain responses to the intrinsically pleasant pictures that were statistically non-significant, after a correction for multiple comparisons. However, this limitation will likely confront any researcher who seeks to examine drug use endophenotypes that are more complex than smoker/non-smoker or nicotine dependence status. Second, we did not include a control group and only measured ERP during conditions of relative nicotine satiation, at baseline. We were thus unable to determine whether the reward system alterations we observed were specific to drug dependence or whether they would be exacerbated by protracted withdrawal in this study, as is predicted by recent addiction models [e.g., Ref. (2)]. Third, we were unable to separate out the pharmacological effects from the behavioral effects of smoking on LPP response, an issue that could be addressed by the use of blinded placebo cigarettes. Finally, it is possible that these genotypes we identified are markers for individuals with trait-level dysphoria or anhedonia, with smoking merely being a means by which these individuals "self-medicate" for deficiencies in their brain's DA-mediated reward system (30). However, the participants in our sample did not differ by genotype on several questionnaire measures that are presumably sensitive to trait-level differences in affective predisposition. Indeed, the lack of association between the genotypes and our baseline measures of smoking dependence and trait affective disposition strengthens the clinical relevance of our IRS group measure and highlights the potential relevance of the LPP grouping as an endophenotype for predicting treatment response.

Future studies should examine whether the IRS- endophenotype is found among those with other drug abuse disorders and those from a healthy population to determine the extent to the IRS- endophenotype represents a risk factor specific to addiction. The relationship between this endophenotype and the development of nicotine dependence should be examined among adolescents at risk for nicotine dependence. This endophenotype should be replicated and extended by using imaging technology to more precisely identify related regions of the brain. The relationship between IRS group and other endophenotypes related to reward, such as impulsivity (94), should be investigated. Finally, the relationship between the IRS group endophenotype and other genetic polymorphisms related to the brain's reward system and nicotine dependence should be examined, including dopamine D4 receptor (DRD4) (95) and DA transporter (SLC6A3) (96) genes.

\section{CONCLUSION}

In conclusion, these results suggest that polymorphisms of genes influencing $\mathrm{nAChR}$ expression are related to a neural marker of reward sensitivity in smokers, a marker that may be a clinically useful endophenotype for identifying smokers at risk for relapse. In particular, the CHRNA3 rs578776 was found to predict membership in clusters that varied by reward sensitivity to natural and cigarette stimuli and that predicted smoking cessation outcome. These results suggest that an endophenotype comprised of ERP measures of motivational salience can be a valuable tool 
for studying the interplay between drug dependence, genetics, and brain alterations thought to maintain dependence and as a diagnostic marker for identifying smokers who are at greater risk for relapse and who may need cessation interventions tailored to address their hyposensitivity to intrinsically reinforcing stimuli.

\section{REFERENCES}

1. Goldstein RZ, Volkow ND. Drug addiction and its underlying neurobiological basis: neuroimaging evidence for the involvement of the frontal cortex. Am J Psychiatry (2002) 159:1642-52. doi:10.1176/ appi.ajp.159.10.1642

2. Koob GF, Volkow ND. Neurocircuitry of addiction. Neuropsychopharmacology (2010) 35:217-38. doi:10.1038/npp.2009.110

3. Volkow ND, Wang GJ, Fowler JS, Tomasi D, Telang F, Baler R. Addiction: decreased reward sensitivity and increased expectation sensitivity conspire to overwhelm the brain's control circuit. Bioessays (2010) 32:748-55. doi:10.1002/bies. 201000042

4. Bradley BP, Mogg K, Wright T, Field M. Attentional bias in drug dependence: vigilance for cigarette-related cues in smokers. Psychol Addict Behav (2003) 17:66-72. doi:10.1037/0893-164X. 17.1 .66

5. Franken IH. Drug craving and addiction: integrating psychological and neuropsychopharmacological approaches. Prog Neuropsychopharmacol Biol Psychiatry (2003) 27:563-79. doi:10.1016/S02785846(03)00081-2

6. Littel M, Franken IH. Implicit and explicit selective attention to smoking cues in smokers indexed by brain potentials. J Psychopharmacol (2011) 25:503-13. doi:10.1177/ 0269881110379284

7. Mogg K, Bradley BP, Field M, De Houwer J. Eye movements to smoking-related pictures in smokers: relationship between attentional biases and implicit and explicit measures of stimulus valence. Addiction (2003) 98:825-36. doi:10.1046/j.13600443.2003.00392.x

8. Bauer D, Cox WM. Alcohol-related words are distracting to both alcohol abusers and non-abusers in the Stroop colour-naming task. Addiction (1998) 93:1539-42. doi:10.1046/j.1360-0443.1998. 9310153910.x

9. Ryan F. Attentional bias and alcohol dependence: a controlled study using the modified Stroop paradigm. Addict Behav (2002)
27:471-82. doi:10.1016/S03064603(01)00183-6

10. Dunning JP, Parvaz MA, Hajcak G, Maloney T, Alia-Klein N, Woicik $\mathrm{PA}$, et al. Motivated attention to cocaine and emotional cues in abstinent and current cocaine users an ERP study. Eur J Neurosci (2011) 33:1716-23. doi:10.1111/j. 1460-9568.2011.07663.x

11. Lubman DI, Allen NB, Peters LA, Deakin JF. Electrophysiological evidence that drug cues have greater salience than other affective stimuli in opiate addiction. JPsychophysiol (2008) 22:836-42. doi:10.1177/ 0269881107083846

12. Lubman DI, Yucel M, Kettle JW, Scaffidi A, Mackenzie T, Simmons JG, et al. Responsiveness to drug cues and natural rewards in opiate addiction: associations with later heroin use. Arch Gen Psychiatry (2009) 66:205-12. doi:10.1001/ archgenpsychiatry.2008.522

13. Grigson PS, Twining RC. Cocaineinduced suppression of saccharin intake: a model of drug-induced devaluation of natural rewards. Behav Neurosci (2002) 116:321-33. doi:10.1037/0735-7044.116.2.321

14. Wyvell CL, Berridge KC. Incentive sensitization by previous amphetamine exposure: increased cue-triggered "wanting" for sucrose reward. J Neurosci (2001) 21:7831-40.

15. Goldstein RZ, Woicik PA, Moeller SJ, Telang F, Jayne M, Wong C, et al. Liking and wanting of drug and non-drug rewards in active cocaine users: the STRAP-R questionnaire. $J$ Psychopharmacol (2010) 24:257-66. doi:10.1177/0269881108096982

16. Versace F, Robinson JD, Lam CY, Minnix JA, Brown VL, Carter BL, et al. Cigarette cues capture smokers' attention: evidence from eventrelated potentials. Psychophysiology (2010) 47:435-41. doi:10.1111/ j.1469-8986.2009.00946.x

17. Wrase J, Schlagenhauf F, Kienast T, Wustenberg T, Bermpohl F, Kahnt $\mathrm{T}$, et al. Dysfunction of reward processing correlates with alcohol craving in detoxified alcoholics. Neuroimage (2007) 35:787-94. doi:10. 1016/j.neuroimage.2006.11.043

18. Versace F, Lam CY, Engelmann JM, Robinson JD, Minnix JA, Brown

\section{ACKNOWLEDGMENTS}

The authors wish to thank Krystle Bartley, Dr. Victoria L. Brown, Jennifer Canul, Janeene Frerking, Christine Jeria, Paul Longoria, Samuel W. Miller, Kevin Mulpur, Cissette Muster, Tiffany Rattler, and Susana Torres for help in data collection.

VL, et al. Beyond cue reactivity: blunted brain responses to pleasant stimuli predict long term smoking abstinence. Addict Bio (2012) 17:991-1000. doi:10.1111/j. 1369-1600.2011.00372.x

19. Amrhein C, Muhlberger A, Pauli P, Wiedemann G. Modulation of event-related brain potentials during affective picture processing: a complement to startle reflex and skin conductance response? Int J Psychophysiol (2004) 54:231-40. doi:10.1016/j.ijpsycho. 2004.05.009

20. Codispoti M, Ferrari V, Bradley MM. Repetition and event-related potentials: distinguishing early and late processes in affective picture perception. J Cogn Neurosci (2007) 19:577-86. doi:10.1162/jocn.2007. 19.4 .577

21. Cuthbert BN, Schupp HT, Bradley MM, Birbaumer N, Lang PJ. Brain potentials in affective picture processing: covariation with autonomic arousal and affective report. Biol Psychol (2000) 52:95-111. doi:10. 1016/S0301-0511(99)00044-7

22. Schupp HT, Cuthbert BN, Bradley MM, Cacioppo JT, Ito T, Lang PJ. Affective picture processing: the late positive potential is modulated by motivational relevance. Psychophysiology (2000) 37:257-61. doi:10. 1111/1469-8986.3720257

23. Weinberg A, Hajcak G. Beyond good and evil: the time-course of neural activity elicited by specific picture content. Emotion (2010) 10:767-82. doi:10.1037/a0020242

24. Robinson TE, Berridge KC. The neural basis of drug craving: an incentive-sensitization theory of addiction. Brain Res Rev (1993) 18:247-91. doi:10.1016/01650173(93)90013-P

25. McDonough BE, Warren CA. Effects of 12-h tobacco deprivation on event-related potentials elicited by visual smoking cues. Psychopharmacology (Berl) (2001) 154:282-91. doi:10.1007/s002130000647

26. Versace F, Minnix JA, Robinson JD, Lam CY, Brown VL, Cinciripini PM. Brain reactivity to emotional, neutral and cigarette-related stimuli in smokers. Addict Biol (2011) 16:296-307. doi:10.1111/j. 1369- 1600.2010.00273.x
27. Warren CA, McDonough BE. Eventrelated brain potentials as indicators of smoking cue-reactivity. Clin $\mathrm{Neu}$ rophysiol (1999) 110:1570-84. doi: 10.1016/S1388-2457(99)00089-9

28. Pidoplichko VI, DeBiasi M, Williams JT, Dani JA. Nicotine activates and desensitizes midbrain dopamine neurons. Nature (1997) 390:401-4. doi:10.1038/37120

29. Wise RA, Rompre PP. Brain dopamine and reward. Annu Rev Psychol (1989) 40:191-225. doi:10. 1146/annurev.ps.40.020189.001203

30. Blum K, Sheridan PJ, Wood RC, Braverman ER, Chen TJ, Cull JG, et al. The D2 dopamine receptor gene as a determinant of reward deficiency syndrome. J R Soc Med (1996) 89:396-400.

31. Blum K, Gardner E, Oscar-Berman M, Gold M. "Liking" and "wanting" linked to reward deficiency syndrome (RDS): hypothesizing differential responsivity in brain reward circuitry. Curr Pharm Des (2012) 18:113-8. doi:10.2174/138161212798919110

32. Volkow ND, Wang GJ, Fowler JS, Thanos P, Logan J, Gatley SJ, et al. Brain DA D2 receptors predict reinforcing effects of stimulants in humans: replication study. Synapse (2002) 46:79-82. doi:10.1002/syn. 10137

33. Volkow ND, Wang GJ, Fowler JS, Logan J, Gatley SJ, Wong C, et al. Reinforcing effects of psychostimulants in humans are associated with increases in brain dopamine and occupancy of D2 receptors. J Pharmacol Exp Ther (1999) 291:409-15.

34. Heinz A, Knable MB, Coppola R, Gorey JG, Jones DW, Lee KS, et al. Psychomotor slowing, negative symptoms and dopamine receptor availability - an IBZM SPECT study in neuroleptic-treated and drugfree schizophrenic patients. Schizophr Res (1998) 31:19-26. doi:10. 1016/S0920-9964(98)00003-6

35. Schmidt K, Nolte-Zenker B, Patzer J, Bauer M, Schmidt LG, Heinz A. Psychopathological correlates of reduced dopamine receptor sensitivity in depression, schizophrenia, and opiate and alcohol dependence. Pharmacopsychiatry (2001) 34:66-72. doi:10.1055/s2001-15184 
36. Neville MJ, Johnstone EC, Walton RT. Identification and characterization of ANKK1: a novel kinase gene closely linked to DRD2 on chromosome band 11q23.1. Hum Mutat (2004) 23:540-5. doi:10. 1002/humu.20039

37. Ritchie T, Noble EP. Association of seven polymorphisms of the D2 dopamine receptor gene with brain receptor-binding characteristics. Neurochem Res (2003) 28:73-82. doi:10.1023/A:1021648128758

38. Jönsson EG, Nöthen MM, Grünhage F, Farde L, Nakashima Y, Propping $\mathrm{P}$, et al. Polymorphisms in the dopamine D2 receptor gene and their relationships to striatal dopamine receptor density of healthy volunteers. Mol Psychiatry (1999) 4:290-6. doi:10.1038/sj.mp. 4000532

39. Hauge XY, Grandy DK, Eubanks JH, Evans GA, Civelli O, Litt M. Detection and characterization of additional DNA polymorphisms in the dopamine D2 receptor gene. Genomics (1991) 10:527-30. doi:10. 1016/0888-7543(91)90431-D

40. Comings DE, Ferry L, BradshawRobinson S, Burchette R, Chiu C, Muhleman D. The dopamine D2 receptor (DRD2) gene: a genetic risk factor in smoking. Pharmacogenetics (1996) 6:73-9. doi:10.1097/ 00008571-199602000-00006

41. De Ruyck K, Nackaerts K, Beels L, Werbrouck J, De Volder A, Meysman M, et al. Genetic variation in three candidate genes and nicotine dependence, withdrawal and smoking cessation in hospitalized patients. Pharmacogenomics (2010) 11:1053-63. doi:10.2217/ PGS.10.75

42. Munafò MR, Johnstone EC, Murphy MF, Aveyard P. Lack of association of DRD2 rs1800497 (Taq1A) polymorphism with smoking cessation in a nicotine replacement therapy randomized trial. Nicotine Tob Res (2009) 11:404-7. doi:10.1093/ ntr/ntp007

43. David SP, Niaura R, Papandonatos GD, Shadel WG, Burkholder GJ, Britt DM, et al. Does the DRD2-Taq1 A polymorphism influence treatment response to bupropion hydrochloride for reduction of the nicotine withdrawal syndrome? Nicotine Tob Res (2003) 5:935-42. doi:10.1080/ 14622200310001615295

44. Robinson JD, Lam CY, Minnix JA, Wetter DW, Tomlinson GE, Minna JD, et al. The DRD2 TaqI$\mathrm{B}$ polymorphism and its relationship to smoking abstinence and withdrawal symptoms. Pharmacogenomics J (2007) 7:266-74. doi:10.1038/sj.tpj.6500427

45. David SP, Strong DR, Munafo MR, Brown RA, Lloyd-Richardson EE, Wileyto PE, et al. Bupropion efficacy for smoking cessation is influenced by the DRD2 Taq1A polymorphism: analysis of pooled data from two clinical trials. Nicotine Tob Res (2007) 9:1251-7. doi:10.1080/ 14622200701705027

46. Lerman C, Jepson C, Wileyto EP, Epstein LH, Rukstalis M, Patterson F, et al. Role of functional genetic variation in the dopamine D2 receptor (DRD2) in response to bupropion and nicotine replacement therapy for tobacco dependence: results of two randomized clinical trials. Neuropsychopharmacology (2006) 31:231-42. doi:10. 1038/sj.npp.1300861

47. Johnstone EC, Yudkin PL, Hey K, Roberts SJ, Welch SJ, Murphy MF, et al. Genetic variation in dopaminergic pathways and short-term effectiveness of the nicotine patch. Pharmacogenetics (2004) 14:83-90. doi:10.1097/01. fpc.0000054154.92680.6d

48. Yudkin P, Munafo M, Hey K, Roberts S, Welch S, Johnstone E, et al. Effectiveness of nicotine patches in relation to genotype in women versus men: randomised controlled trial. BMJ (2004) 328:989-90. doi: 10.1136/bmj.38050.674826

49. Stapleton JA, Sutherland G, O'Gara C, Spirling LI, Ball D. Association between DRD2/ANKK1 Taq1A genotypes, depression and smoking cessation with nicotine replacement therapy. Pharmacogenet Genomics (2011) 21:447-53. doi:10.1097/ FPC.0b013e328347473a

50. Perkins KA, Lerman C, Grottenthaler A, Ciccocioppo MM, Milanak $\mathrm{M}$, Conklin CA, et al. Dopamine and opioid gene variants are associated with increased smoking reward and reinforcement owing to negative mood. Behav Pharmacol (2008) 19:641-9. doi:10.1097/FBP. 0b013e32830c367c

51. Zuo Y, Gilbert DG, Rabinovich NE, Riise H, Needham R, Huggenvik JI. DRD2-related TaqIA polymorphism modulates motivation to smoke. Nicotine Tob Res (2009) 11:1321-9. doi:10.1093/ntr/ntp141

52. Corrigall WA, Coen KM, Adamson KL. Self-administered nicotine activates the mesolimbic dopamine system through the ventral tegmental area. Brain Res (1994) 653:278-84. doi:10.1016/00068993(94)90401-4
53. Brody AL, Mandelkern MA, London ED, Olmstead RE, Farahi J, Scheibal $\mathrm{D}$, et al. Cigarette smoking saturates brain alpha 4 beta 2 nicotinic acetylcholine receptors. Arch Gen Psychiatry (2006) 63:907-15. doi:10.1001/ archpsyc.63.8.907

54. Toll L, Zaveri NT, Polgar WE, Jiang F, Khroyan TV, Zhou W, et al. AT-1001: a high affinity and selective alpha3beta4 nicotinic acetylcholine receptor antagonist blocks nicotine self-administration in rats. Neuropsychopharmacology (2012) 37:1367-76. doi:10.1038/ npp.2011.322

55. Tapper AR, McKinney SL, Nashmi R, Schwarz J, Deshpande P, Labarca $C$, et al. Nicotine activation of alpha4* receptors: sufficient for reward, tolerance, and sensitization. Science (2004) 306:1029-32. doi:10. 1126/science. 1099420

56. Gotti C, Guiducci S, Tedesco V, Corbioli S, Zanetti L, Moretti M, et al. Nicotinic acetylcholine receptors in the mesolimbic pathway: primary role of ventral tegmental area alpha6beta ${ }^{*}$ receptors in mediating systemic nicotine effects on dopamine release, locomotion, and reinforcement. $J \mathrm{Neu}$ rosci (2010) 30:5311-25. doi:10. 1523/JNEUROSCI.5095-09.2010

57. Markou A, Paterson NE. The nicotinic antagonist methyllycaconitine has differential effects on nicotine self-administration and nicotine withdrawal in the rat. Nicotine Tob Res (2001) 3:361-73. doi: 10.1080/14622200110073380

58. Picciotto MR, Zoli M, Rimondini R, Lena C, Marubio LM, Pich EM, et al. Acetylcholine receptors containing the beta2 subunit are involved in the reinforcing properties of nicotine. Nature (1998) 391:173-7. doi: $10.1038 / 34413$

59. Kenny PJ, Markou A. Nicotine self-administration acutely activates brain reward systems and induces a long-lasting increase in reward sensitivity. Neuropsychopharmacology (2006) 31:1203-11. doi:10. 1038/sj.npp.1300905

60. Dutra SJ, Stoeckel LE, Carlini SV, Pizzagalli DA, Evins AE. Varenicline as a smoking cessation aid in schizophrenia: effects on smoking behavior and reward sensitivity. Psychopharmacology (Berl) (2012) 219:25-34 doi:10.1007/s00213-011-2373-6

61. Conlon MS, Bewick MA. Single nucleotide polymorphisms in CHRNA5 rs16969968, CHRNA3 rs578776, and LOC123688 rs8034191 are associated with heaviness of smoking in women in northeastern Ontario, Canada. Nicotine Tob Res (2011) 13:498-503. doi:10.1093/ntr/ntr140

62. Falcone M, Jepson C, Benowitz N, Bergen AW, Pinto A, Wileyto $\mathrm{EP}$, et al. Association of the nicotine metabolite ratio and CHRNA5/CHRNA3 polymorphisms with smoking rate among treatment-seeking smokers. Nicotine Tob Res (2011) 13:498-503. doi:10.1093/ntr/ntr012

63. Saccone NL, Culverhouse RC, Schwantes-An TH, Cannon DS, Chen X, Cichon S, et al. Multiple independent loci at chromosome 15q25.1 affect smoking quantity: a meta-analysis and comparison with lung cancer and COPD. PLoS Genet (2010) 6:e1001053. doi: 10.1371/journal.pgen.1001053

64. Gallego X, Molas S, Amador-Arjona A, Marks MJ, Robles N, Murtra $\mathrm{P}$, et al. Overexpression of the CHRNA5/A3/B4 genomic cluster in mice increases the sensitivity to nicotine and modifies its reinforcing effects. Amino Acids (2012) 43:897-909. doi:10. 1007/s00726-011-1149-y

65. Cinciripini PM, Robinson JD, Karam-Hage M, Minnix JA, Lam CY, Versace F, et al. The effects of varenicline and bupropion-SR plus intensive counseling on prolonged abstinence from smoking, depression, negative affect and other symptoms of nicotine withdrawal. JAMA Psychiatry (2013) 70:522-33. doi:10.1001/jamapsychiatry.2013. 678

66. Sheehan DV, Lecrubier Y, Sheehan $\mathrm{KH}$, Amorim P, Janavs J, Weiller E, et al. The Mini-International Neuropsychiatric Interview (M.I.N.I.): the development and validation of a structured diagnostic psychiatric interview for DSM-IV and ICD-10. J Clin Psychiatry (1998) 59(Suppl 20):22-33.

67. Heatherton TF, Kozlowski LT, Frecker RC, Fagerström KO. The Fagerström test for nicotine dependence: a revision of the Fagerström tolerance questionnaire. Br J Addiction (1991) 86:1119-27. doi:10. 1111/j.1360-0443.1991.tb01879.x

68. Piper ME, Piasecki TM, Federman EB, Bolt DM, Smith SS, Fiore MC, et al. A multiple motives approach to tobacco dependence: the Wisconsin Inventory of Smoking Dependence Motives (WISDM-68). J Consult Clin Psychol (2004) 72:139-54. doi:10.1037/a0013298

69. Radloff LS. The CES-D scale: a selfreport depression scale for research 
in the general population. Appl Psychol Meas (1977) 1:385-401. doi:10. 1177/014662167700100306

70. Strong DR, Brown RA, Kahler CW, Lloyd-Richardson EE, Niaura R. Depression proneness in treatmentseeking smokers: a taxometric analysis. Pers Individ Dif (2004) 36:1155-70. doi:10.1016/S01918869(03)00207-1

71. Carver CS, White TL. Behavioral inhibition, behavioral activation, and affective responses to impending reward and punishment: the BIS/BAS scales. J Pers Soc Psychol (1994) 67:319-33. doi:10.1037/ 0022-3514.67.2.319

72. Fawcett J, Clark DC, Scheftner WA, Gibbons RD. Assessing anhedonia in psychiatric patients. Arch Gen Psychiatry (1983) 40:79-84. doi:10.1001/archpsyc. 1983.01790010081010

73. Lang PJ, Bradley MM, Cuthbert BN. International Affective Picture System (IAPS): Affective Ratings of Pictures and Instruction Manual. Technical Report A-8. Gainesville, FL: University of Florida (2008).

74. Gilbert DG, Rabinovich NE. The International Smoking Image Series (with Neutral Counterparts), v. 1.2. Carbondale, IL: Southern Illinois University (1999).

75. Stritzke WG, Breiner MJ, Curtin JJ, Lang AR. Assessment of substance cue reactivity: advances in reliability, specificity, and validity. Psychol Addict Behav (2004) 18:148-59. doi: 10.1037/0893-164X.18.2.148

76. Carter BL, Robinson JD, Lam CY, Wetter DW, Day SX, Tsan JY, et al. A psychometric evaluation of cigarette stimuli used in a cue reactivity study. Nicotine Tob Res (2006) 8:361-9. doi:10.1080/ 14622200600670215

77. Ille N, Berg P, Scherg M. Artifact correction of the ongoing EEG using spatial filters based on artifact and brain signal topographies. J Clin Neurophysiol (2002) 19:113-24. doi:10.1097/00004691200203000-00002

78. Junghöfer $M$, Elbert $T$, Tucker DM, Rockstroh B. Statistical control of artifacts in dense array EEG/MEG studies. Psychophysiology (2000) 37:523-32. doi:10.1111/ 1469-8986.3740523
79. Keil A, Bradley MM, Hauk O, Rockstroh B, Elbert T, Lang PJ. Largescale neural correlates of affective picture processing. Psychophysiology (2002) 39:641-9. doi:10.1111/14698986.3950641

80. Olofsson JK, Nordin S, Sequeira $\mathrm{H}$, Polich J. Affective picture processing: an integrative review of ERP findings. Biol Psychol (2008) 77:247-65. doi:10.1016/j. biopsycho.2007.11.006

81. Schupp HT, Flaisch T, Stockburger J, Junghöfer M. Emotion and attention: event-related brain potential studies. Prog Brain Res (2006) 156:31-51. doi:10.1016/ S0079-6123(06)56002-9

82. Hair FJ, Black WC. Cluster analysis. In: Grimm LG, Yarnold PR, editors. Reading and Understanding More Multivariate Statistics. Washington, DC: American Psychological Association (2000). p. 147-205.

83. Hartigan JA, Wong MA. Algorithm AS 136: a K-means clustering algorithm. J R Stat Soc C (1979) 28:100-8.

84. Sarle WS. SAS Technical Report A108, Cubic Clustering. Cary, NC: Cubic Clustering Criterion (1983).

85. Duda RO, Hart PE. Pattern Classification and Scene Analysis. New York: John Wiley and Sons (1973).

86. Macmillan NA, Creelman CD. Detection Theory: A User's Guide. Mahwah, NJ: Lawrence Erlbaum (2004).

87. Bierut LJ, Stitzel JA, Wang JC, Hinrichs AL, Grucza RA, Xuei X, et al. Variants in nicotinic receptors and risk for nicotine dependence. Am J Psychiatry (2008) 165:1163-71. doi:10.1176/appi.ajp. 2008.07111711

88. Saccone NL, Wang JC, Breslau N, Johnson EO, Hatsukami D, Saccone SF, et al. The CHRNA5-CHRNA3CHRNB4 nicotinic receptor subunit gene cluster affects risk for nicotine dependence in AfricanAmericans and in EuropeanAmericans. Cancer Res (2009) 69:6848-56. doi:10.1158/00085472.CAN-09-0786

89. Weiss RB, Baker TB, Cannon DS, von Niederhausern NA, Dunn DM, Matsunami N, et al. A candidate gene approach identifies the CHRNA5-A3-B4 region as a risk factor for age-dependent nicotine addiction. PLoS Genet (2008) 4:e1000125. doi:10.1371/ journal.pgen. 1000125

90. Stevens VL, Bierut LJ, Talbot JT, Wang JC, Sun J, Hinrichs AL, et al. Nicotinic receptor gene variants influence susceptibility to heavy smoking. Cancer Epidemiol Biomarkers Prev (2008) 17:3517-25. doi:10.1158/1055-9965.EPI-080585

91. Hong LE, Hodgkinson CA, Yang Y Sampath H, Ross TJ, Buchholz B, et al. A genetically modulated, intrinsic cingulate circuit supports human nicotine addiction. Proc Natl Acad Sci U S A (2010) 107:13509-14. doi:10.1073/pnas.1004745107

92. Barr RS, Pizzagalli DA, Culhane MA, Goff DC, Evins AE. A single dose of nicotine enhances reward responsiveness in nonsmokers: implications for development of dependence. Biol Psychiatry (2008) 63:1061-5. doi:10.1016/j.biopsych. 2007.09.015

93. Fiorino DF, Phillips AG. Facilitation of sexual behavior in male rats following $d$ amphetamine-induced behavioral sensitization. Psychopharmacology (Berl) (1999) 142:200-8. doi:10.1007/s002130050880

94. Moallem NR, Ray LA. Dimensions of impulsivity among heavy drinkers, smokers, and heavy drinking smokers: singular and combined effects. Addict Behav (2012) 37:871-4. doi:10.1016/j.addbeh.2012.03.002

95. McClernon FJ, Hutchison KE, Rose JE, Kozink RV. DRD4 VNTR polymorphism is associated with transient fMRI-BOLD responses to smoking cues. Psychopharmacology (Berl) (2007) 194:433-41. doi:10. 1007/s00213-007-0860-6

96. Erblich J, Lerman C, Self DW, Diaz GA, Bovbjerg DH. Effects of dopamine $\mathrm{D} 2$ receptor (DRD2) and transporter (SLC6A3) polymorphisms on smoking cue-induced cigarette craving among AfricanAmerican smokers. Mol Psychiatry (2005) 10:407-14. doi:10.1038/ sj.mp. 4001588

Conflict of Interest Statement: This study was sponsored by the National
Institute on Drug Abuse through grant R01 DA017073 to Paul M. Cinciripini. Other support included a NIDA sponsored K23 DA024697 to Jason Robinson, and a faculty fellowship from The University of Texas MD Anderson Cancer Center Duncan Family Institute for Cancer Prevention and Risk Assessment to Francesco Versace and the National Institutes of Health through MD Anderson's Cancer Center Support Grant (P30 CA016672). Dr. Paul M. Cinciripini served on the scientific advisory board of Pfizer Pharmaceuticals, conducted educational talks sponsored by Pfizer on smoking cessation (2006-2008), and has received grant support from Pfizer. Dr. Karam-Hage has conducted educational talks sponsored by Pfizer Pharmaceuticals, and has participated as study physician and co-investigator in two studies funded by Pfizer Pharmaceuticals. In 2011, Dr. Versace received an independently reviewed competitive grant supported by Pfizer (Global Research Award for Nicotine Dependence). The other authors declare no conflict of interest.

Received: 09 July 2013; accepted: 06 September 2013; published online: 23 September 2013.

Citation: Robinson JD, Versace F, Lam $C Y$, Minnix JA, Engelmann JM, Cui $Y$, Karam-Hage $M$, Shete SS, Tomlinson GE, Chen TT-L, Wetter DW, Green $C E$ and Cinciripini PM (2013) The CHRNA3 rs578776 variant is associated with an intrinsic reward sensitivity deficit in smokers. Front. Psychiatry 4:114. doi: 10.3389/fpsyt.2013.00114

This article was submitted to Addictive Disorders and Behavioral Dyscontrol, a section of the journal Frontiers in Psychiatry.

Copyright (c) 2013 Robinson, Versace, Lam, Minnix, Engelmann, Cui, KaramHage, Shete, Tomlinson, Chen, Wetter, Green and Cinciripini. This is an openaccess article distributed under the terms of the Creative Commons Attribution License (CC BY). The use, distribution or reproduction in other forums is permitted, provided the original author (s) or licensor are credited and that the original publication in this journal is cited, in accordance with accepted academic practice. No use, distribution or reproduction is permitted which does not comply with these terms. 